\title{
Septicaemia in an adolescent presenting with potentially fatal CA MRSA osteomyelitis
}

\author{
Teresa Pena Fernandes, ${ }^{1}$ Marlene Rodrigues, ${ }^{2}$ Joana Cunha Oliveira, ${ }^{2}$ Augusto Ribeiro ${ }^{3}$
}

'Department of Paediatrics, Centro Hospitalar Tamega e Sousa EPE, Guilhufe, Portugal ${ }^{2}$ Department of Paediatrics, Hospital de Braga, Braga, Portugal

${ }^{3}$ Paediatric Intensive Care Unit, Centro Hospitalar de Sao Joao EPE, Porto, Portugal

\section{Correspondence to} Dr Teresa Pena Fernandes, teresa.pena.fernandes@gmail. com

Accepted 24 August 2018

\section{DESCRIPTION}

A 14-year-old boy, with no prior medical history, presented with tenderness on the right knee after minor trauma while playing football the previous day. On physical examination, there were minor inflammatory signs, with no penetrating wound and he was sent home.

Two days later, due to worsening symptoms, MRI of the lower limb was performed and revealed multiple tibial lytic lesions, intraosseous abscesses and diffuse soft tissue oedema (figure 1).

Surgical debridement was performed and flucloxacillin and amikacin were initiated. The following day, his clinical status deteriorated with septic shock and respiratory failure. He was admitted in the paediatric intensive care unit.

Preoperatory blood cultures identified a methicillin-resistant Staphylococcus aureus (MRSA) Panton-Valentine leucocidin (PVL) positive and antimicrobial therapy was changed to ceftriaxone and vancomycin. Fasciotomy of the four leg fascial compartments was performed, with skin closure using a shoelace technique (figure 2).

Eight days later, due persistent fever, the antimicrobial therapy was changed to clindamycin and vacuum systems were placed on the fasciotomies with instillation system every 4 hours.

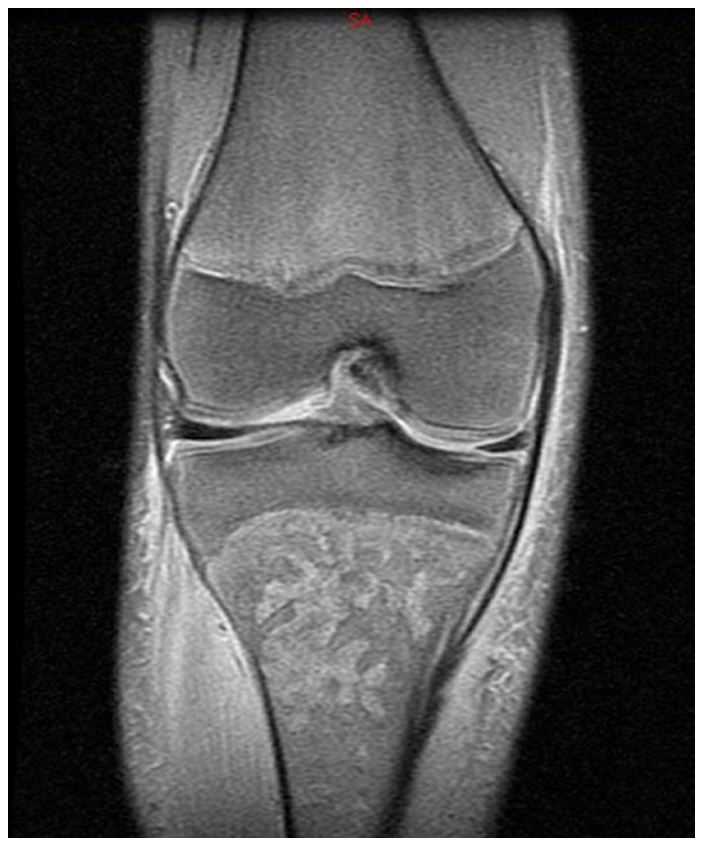

Figure 1 Lower limb MRI imaging revealed multiple serpiginous lytic lesions in the proximal tibial metaphyseal region suggesting intraosseous abscesses.

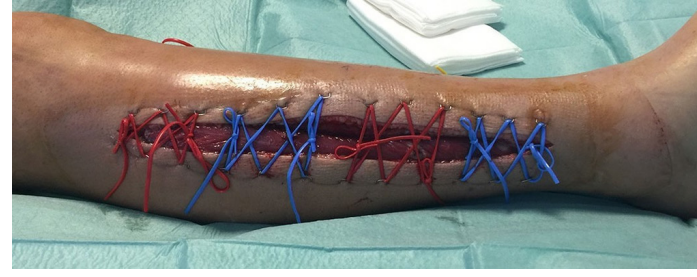

Figure 2 After surgical debridement, wound closure was achieved using an elastic suture with a shoelace technique.

There was a favourable clinical evolution and he completed 8 weeks of antibiotic therapy.

After infection control was achieved, he started daily physiotherapy for a total of 6 months after discharge. He recovered with no functional limitation. On follow-up, there were no signs of recurrent musculoskeletal or other form of staphylococcal infection.

Osteomyelitis is an infection of the bone and in children it is usually caused by bacteria that reach the bone haematogenously. Other pathogenic mechanisms include direct inoculation (usually traumatic, but also surgical) or local invasion from a contiguous infection.

In half of the cases, no pathogen is isolated. While among toddlers, Kingella kingae is the most common cause of osteomyelitis, in adolescents, Staphylococcus aureus is the most common microorganism and community-acquired (CA) MRSA is the most severe pathogen. ${ }^{1}$ MRSA infections have ceased to be exclusively associated with hospital environment and are becoming an emerging problem in

Learning points

Methicillin-resistant Staphylococcus aureus (MRSA) infections are becoming an emerging problem in the community and Panton-Valentine leucocidin is associated with increased virulence of MRSA strains.

- There should be a high level of suspicion for this pathogen even in children without any risk factor, in order to avoid delays in diagnosis and treatment, with potentially worse prognosis.

- The diagnosis of osteomyelitis needs to be considered in the setting of trauma with bony point tenderness on examination. Blood testing with $C$ reactive protein/erythrocyte sedimentation rate and imaging may assist the diagnosis. Prompt clinical follow-up should be secured if symptoms do not resolve. 
the community. ${ }^{2}$ Outbreaks of CA MRSA infections have been reported worldwide, although prevalence varied geographically with lower incidence in northern Europe. CA MRSA is responsible for an increasing number of invasive musculoskeletal infections in healthy children even in the absence of risk factors and it differs from hospital-acquired MRSA as it is usually associated with more aggressive diseases. ${ }^{2}$

PVL, first described in 1932, is associated with an increased virulence of MRSA strains. ${ }^{1-3}$ It is cytotoxic and is mostly associated with pulmonary or cutaneous infections. It is present in approximately $5 \%$ of MRSA strains in hospitals and practically in all CA MRSA. ${ }^{1}$

With this case, we intend to highlight the importance of an early diagnosis of a CA MRSA infection in a previously healthy child because it can be an extremely aggressive pathogen, leading to potentially life-threatening complications. Prompt empiric antibiotic therapy with timely surgical debridement is paramount for survival and functional recovery.
Contributors All the authors were involved in case management and diagnosis. TPF, MR and JCO collected the data. TPF wrote the article and AR served as scientific advisor. All the authors made a critical revision of the article and approved this final version to be published.

Funding The authors have not declared a specific grant for this research from any funding agency in the public, commercial or not-for-profit sectors.

Competing interests None declared.

Patient consent Parental/guardian consent obtained.

Provenance and peer review Not commissioned; externally peer reviewed.

\section{REFERENCES}

1 Pendleton A, Kocher MS. Methicillin-resistant staphylococcus aureus bone and joint infections in children. J Am Acad Orthop Surg 2015;23:29-37.

2 Vander Have KL, Karmazyn B, Verma M, et al. Community-associated methicillinresistant Staphylococcus aureus in acute musculoskeletal infection in children: a game changer. J Pediatr Orthop 2009;29:927-31.

3 Sarkissian EJ, Gans I, Gunderson MA, et al. Community-acquired Methicillin-resistant Staphylococcus aureus Musculoskeletal Infections: Emerging Trends Over the Past Decade. J Pediatr Orthop 2016;36:323-7.

Copyright 2018 BMJ Publishing Group. All rights reserved. For permission to reuse any of this content visit

http://group.bmj.com/group/rights-licensing/permissions.

BMJ Case Report Fellows may re-use this article for personal use and teaching without any further permission.

Become a Fellow of BMJ Case Reports today and you can:

- Submit as many cases as you like

- Enjoy fast sympathetic peer review and rapid publication of accepted articles

- Access all the published articles

Re-use any of the published material for personal use and teaching without further permission

For information on Institutional Fellowships contact consortiasales@bmjgroup.com

Visit casereports.bmj.com for more articles like this and to become a Fellow 